\title{
The importance of vocational ethics in paramedic education, vocational ethics course for paramedics
}

\author{
Ahu Pakdemirli ${ }^{\text {1a }}$, Bennur Koca ${ }^{1}$ \\ ${ }^{1}$ Vocational Higher School of Healthcare Studies, Dokuz Eylul University, Izmir, Turkey
}

\begin{abstract}
Ethics are rules of behaviors which morally good or bad. Bioethics is the study of ethics about by advances in biology and medicine. Health care providers should have knowledge about health professional ethics principles, public officials' ethical behavior principles and ethical principles concerned about other legislation. They should find the required information to make logical, objective and accurate decisions where they may face with ethical problems in their professional life. Unfortunately in our country there isn't any special vocational ethics course designed for paramedics. Our aim is to design a Vocational Ethics Course for Paramedics which includes all issues of bioethics.
\end{abstract}

\section{Introduction}

Ethics is important in every area of human life such as education, health, economics, and politics. The importance of ethics in our country over the last 40 years began to increase both as scope and training period. Although not yet sufficient enough, educational institutions, support academic meetings and their libraries give part to publications relating to ethics, [2], [3], [16].

Both new value definition issues in daily medical practice, and from the nature of the medicine such as continuous improvement and changing area and thus it contains ethical dilemmas; health employees must keep their interaction with ethics alive. The knowledge of legislation information and the legal responsibility necessary during the execution of the profession also refers to keep in mind the dimension of the relationship, [16].

Paramedic programs in our country, professional / vocational ethics education, class hours, curriculum, lecture book, lecture notes, qualification of the lecturer, term of the lectures to be provided, method of the lectures, and the likely standardization issues have not yet been determined and the need for regulation is obvious because of its drawbacks.

However, overall the place of ethics in paramedic training is basically limited to the period before graduation. After graduation, training provided for paramedics; knowledge,

\footnotetext{
${ }^{a}$ Corresponding author: ahu.pakdemirli@deu.edu.tr
} 
skills and attitudes are expected to take place in their professional life. This is only possible by maintaining contact with the ethical issues in terms of academic and intellectual sense. It is considered to be important that high quality and standardized undergraduate courses taken should be supported by on the job training.

\section{Ethics}

Hippocrates, the founder of deontology (460-377 B.C.) mentioned about the approach with love and respect to people while health providing, priority to moral values and recognize the necessity of being virtuous. In 1834, after the physician Jeremy Bentham's book "Deontology; or, The science of morality", the term of "deontology" started more commonly used. In our country, the word "Deontology" as a discipline is used synonymously with "Ethics" which has a recent usage for the Anglo-Saxon practice, [3].

"Ethics" word is originated from Greek, in Turkish it is the science of morality. The subject of ethics or moral philosophy is human action. All kinds of human activity and action is not the subject of ethics, ethical issues primarily create actions that emphasize morality. Ethical and moral terms can be used interchangeably in most cases. However, when describing the individual moral code of conduct more academic use, it includes ethical standards of professional conduct, [16]. Ethics is the knowledge of what should be done or not, what is desirable and what's not going to be asked, [4].

Ethics is a behavioral science which is a systematic way to investigate the value of human behavior. Ethics is based on sociology-cultural, philosophical and religious beliefs. These beliefs of society consider true or false, good or bad criteria, and immeasurable and cannot be passed from one culture to another. Ethics is based on abstract concepts and also tried to define what should be understood from these abstract concepts. Ethical rules are clear and are expected to include written rules for a particular area. For example, although there are common principles for ethics of art, politics, medicine, law, education, environment, bioethics, media, etc., they contain more of their own principles. These principles are developed based on the concept of universally held, not according to the characteristics of individuals expected to comply, [8], [11].

\subsection{Bioethics}

There must be a bio-psycho-social being human so all other that live with in interaction and therefore of the opinion that it is impossible to assess alone in nature movement worth the trouble of the main issues of people with medical ethics with regard to increasingly place the issue of witness that is to leave the bioethics who all live or evolve when it is, [5]. In this process, "medical ethics education" program will also be taking place in bioethics education. Bioethics examines mainly ethical problems such as organ transplantation and genetic studies due to the developments in medicine and biology, [13]. Indeed, UNESCO accepted Declaration On Science And The Use Of Scientific Knowledge in 1999, the development of science and education in bioethics and it is stated that science ethics should take place in the curriculum prepared within the in the field of science - technology, [13].

\subsection{Professional / Vocational Ethics}

Professional / vocational ethics defined as professional rules of conduct to be followed, particularly in the professions directly relevant to the people. One of the most important aspects of professional ethics, no matter where in the world, individuals working in the same profession is required to behave in accordance with these rules of conduct. 
Relationships between people lies on the basis of professional ethics. Comply with certain behavior patterns in relationships with each other, individuals of the same profession is required by the professional ethics. Professional ethics is always the outcome work of a group. It may remain in force as long as it maintains professional ethics groups and individuals who ordered, forcing them to behave in any way, that draws a limit to personal tendencies and of rules which prevented them from going any further, [5], [8], [11].

Different approaches from different sources related to professional ethics is concerned.

For example;

- Nowadays, the reason of the gradual increase of interest in the professional ethics is that the increase of ethical problems encountered in some occupations or awareness of the growing problem, [13].

- Professional / vocational ethics defined as professional rules of conduct to be followed, particularly in the professions directly relevant to the people.

- One of the most important aspects of professional ethics, no matter where in the world, individuals working in the same profession is required to behave in accordance with these rules of conduct, [12].

- Relationships between people lies on the basis of professional ethics.

- Members of the same profession and professional ethics are required to comply with certain behavior patterns in their relationships with each other, [4].

\subsection{Ethical Codes}

Professional ethics, to be organized as a set of rules to give direction to the practice of the profession and constitutes ethical behavior codes. Ethical codes / guidelines, which are more specific and concrete than principles and regulations are derived from ethical principles. Ethical codes are often created by a professional organization or regulatory body or professional organization of work, [2], [3], [16]. The ethical code of the paramedic profession in our country is not yet developed, the ethical code of the American Association of Emergency Medical Technicians are taken into account. However, paramedic profession-specific ethical codes / guidelines, takes cardinal importance for paramedics to develop; awareness of the moral aspects of the profession, moral sense, care and treatment services in needs of individuals and groups, society, providing guidance to the professional and ethical responsibilities towards the profession.

\section{Ethical training of paramedics}

Ethics and education they complete each other mutually, there is a special proximity with ethics in education. Ethics and education for Socrates, an integral whole, and ethical information directs the educational approach. Accordingly, the real merit is in the student, the role falls to the teacher is to guide the students actions and behavior of potential interest to this virtue occurs, [12].

One of the aims of ethics training "vocational consciousness" gaining has to be of concern; seeing how the students of professional identity formed by detecting its role more realistic and broad terms, should be able to evaluate the effort, [6], [7]. Nowadays experiencing rapid social changes, there is a need for ethical principles in all areas. Ethical problems lead to values problems because of advances in science and technology have increased the importance of ethics in health care, [6]. Paramedic profession, as a part of health care system, requires making the right decision for patients with many issues in the field of application. Paramedics provide more complex decisions than before with expanding the role and functions and they have to take responsibility for these decisions. For making decision; codes of ethics to act ethically, critical practice, clinical experience, 
academic lessons learned, the ability to predict the results and the courage move on is effective. Ensuring the adequacy of ethical training in paramedic training; quality patient care and treatment available and it is important to provide professional roles of the paramedic profession.

Some universities' ethical courses in the paramedic education curriculum in our country are shown in Table 1, [14].

First and Emergency Aid Program students at Dokuz Eylul University Vocational Higher School of Healthcare Studies take professional ethics for 2 hours at their first year. Our course have a wide content such as introduction to Vocational Ethics course, the relation of ethics with philosophy, culture, moral, value and norm concept, notion of ethics, vocation ethics notion and its importance, principles of ethics, ethics dilemma concept, non-ethical behaviors and affecting factors, ethic codes, patient rights, ethical perspectives about euthanasia, abortion, abortus, organ transplant, experimental animal ethics, scientific publication ethics and other ethical subjects. Courses are conducted in an interactive manner with the participation of students as possible. When the course subjects processed with the instructor lecture presentations together with a brief case reports and role-play applications, it makes easier for students to understand the problem and the solution, [15].

There are many studies in the literature about ethical dilemma and ethical conflict where the paramedics face in the field while giving prehospital care, [1], [9], [10]. In this context, it is expected that the ethical dilemmas and unethical behaviors can be fixed by a standardized and high quality ethical education.

Table 1. Distribution of ethical courses in the paramedic education curriculum at some universities in our country

\begin{tabular}{lll}
\hline University & Name of the course & Hours (theoretical) \\
\hline Dokuz Eylul University & Professional Ethics & 2 \\
Ege University & Professional Ethics and Communication & 1 \\
Akdeniz University & Professional Ethics & 1 \\
Hacettepe University & Vocational Ethics & 2 \\
Pamukkale University & Professional Ethics & 1 \\
Inonu University & Professional Ethics & 1 \\
Mardin Artuklu University & Professional Ethics and Communication & 1 \\
Gazi University & Deontology and Professional Ethics & 2 \\
Adnan Menderes University & Professional Ethics & 2 \\
Zonguldak Karaelmas University & Professional Ethics & 2 \\
Uludag University & Professional Ethics & 2 \\
Artvin Coruh University & Professional Ethics & 2 \\
Kocaeli University & Health Law and Medical Ethics & 2 \\
\hline
\end{tabular}




\section{Conclusion}

Professional/vocational ethics education aims, paramedics to be able to act ethically and responsibly, and to become able to give ethical decisions in the professional life. Paramedics put emphasis on ethics training will provide great benefit to patients and their profession, paramedics as ethic trainees will act more prudent and responsible against patients when the positive outcomes monitored. Those who follow vocational ethics of their profession are undoubtedly uphold their professional honor. If paramedics approach the events with the awareness of professional ethics, they also will have acted in accordance with professional principles.

\section{References}

1. Adams JG, et al., Ann Emerg Med. Ethical conflicts in the prehospital setting. Ann Emerg Med. 1992 Oct;21(10):1259-65, (1992).

2. Arda B., Human Rights in terms of Medical Ethics. Modern Medical Ethics, Ed: Erdem AD , Arda B , Jones SM , et al. Nobel Medicine Bookstores. Nobel printing. Pg : 41-52, (2003).

3. Aydin E., Introduction to Medical Ethics, http://www.medinfo.hacettepe.edu.tr/ July, (2007).

4. Aydin IP., Managerial Professional and Organizational Ethics (3rd ed). Pegau Publishing, Ankara. Pg: 71, (2002).

5. Bioethics Glossary, Philosophical Society of Turkey. Ankara; 35, (2005).

6. Buken NO, Buken E., What they say that medical ethics? Journal of continuing medical education ; 11(1):17-21, (2002).

7. Buken NO., Physician-Patient Relationship and Deontology- Medical EthicsImportance of Medical History Lesson. syndrome;16(9): 69-72, (2004).

8. Cevizci A., Introduction to Ethics Istanbul: Engin Publishing. Pg: 3, (2002).

9. Erbay H, et al., Nurs Ethics. Attitudes of prehospital emergency care professionals toward refusal of treatment: A regional survey in Turkey. Nurs Ethics. 2013 Dec 11;21(5):530-539, (2013).

10. Nordby H. BMC Med Ethics., Should paramedics ever accept patients' refusal of treatment or further assessment? BMC Med Ethics. 2013 Nov 4;14:44. doi: 10.1186/1472-6939-14-44, (2013).

11. Oguz Y., Log in Light of Philosophical Approach to Clinical Ethics, Clinical Ethics, Ed: Demirhan AE, Oguz Y, Elcioğlu O et al. Nobel Medicine Bookstore. Tayf Ofset. Istanbul. Pg: 9-25, (2001).

12. Pieper A. Introduction to Ethics. (V.Atayman, G. Sezer, translation). Istanbul: Detail Publishing. Pg:119, (1999).

13. Williams J.R. (2005). Medical Ethics Guidebook. World Medical Association.Translation Civaner M.

14. http://www.yok.gov.tr/web/guest/universitelerimiz (date accessed: 13 May 2015).

15. http://webb.deu.edu.tr/shmyo/(date accessed: 13 May 2015).

16. Elcioğlu PM , Kırımlıglu N., (2003). Principles of Medical Ethics. Modern Medical Ethics, Ed: Erdem AD, Art B, Jones SM, et al. Nobel Medicine Bookstores . Nobel printing. P g: 26-40 . 